\title{
On Causality and Law in Lucretius and Contemporary Cosmology
}

\author{
David Webb
}

i.

Written by Lucretius in the First Century BCE, De Rerum Natura is an elaboration of Epicurean atomism that ranges over the origin of the universe, the formation of worlds, weather systems, the emergence of life and of social order, morality, and much else besides. ${ }^{i}$ It can be picked over for interesting anticipations of modern atomism and of evolutionary theory. Yet, as a materialist account of the emergence of order, it depends on an account of causality and law which has some surprises, and it is on these that I want to focus here. The familiar image of atoms moving and combining may lead one to expect that order in the universe depends ultimately on fixed laws governing the movement of atoms. Although there are some grounds for such a reading, they are not compelling, and Lucretius is otherwise quite clear that order consists of regularities that arise locally, varying from time to time and from place to place. That this theory of local regularities has been eclipsed by the assumption that laws are fixed says more about our own views than those of Lucretius. From the standpoint of contemporary approaches to causality, Lucretius' account can be described as a regularity theory, where the regularities in question are a feature of the world (and not just of our perception of it). But it is distinctive in that cause and effect do not always and everywhere proceed according to the same invariable laws. Instead, causality precedes laws, which, as regularities, emerge locally and evolve along with the phenomena they determine. The causal structure of the universe is therefore real, but radically contingent. This idea sets Lucretius' account apart from almost all existing theories of causality and law. Notable 
exceptions can be found in the work of Charles Sanders Peirce, to some extent in that of Émile Boutroux, and in certain quarters of contemporary cosmology. For example, Peirce writes that "there is room for serious doubt whether the fundamental laws of mechanics hold good for single atoms," and advises that science turn its attention to "a natural history of laws of nature.",ii On his part, Boutroux declares that "it is chance, or destiny, or an ensemble of capricious wills, that presides in the universe." iii However, in this paper I will focus on the work of Lee Smolin, and in particular on his recent collaboration with Roberto Mangabeira Unger, The Singular Universe and the Reality of Time, which presents a comprehensive case for separating causality and law, and recognizing that the laws of nature evolve; an idea he first proposed over twenty years ago in The Life of the Cosmos..$^{\text {iv }}$

Smolin has, for several decades, been at the forefront of research in quantum gravity, which aims to combine the key elements of quantum physics and the theory of general relativity. One of the many challenges this presents is that of bringing together two fundamentally different approaches to space and time. Einstein's general theory of relativity describes space and time as intimately related to events, and as variable according to the perspective or frame of reference one takes up. With no absolute scale of time on which to pin events, a change in perspective may entail a change the order between events. Ascertaining the causal relations between events is therefore crucial to determining the structure of space and time; or, as Smolin puts it, "almost all of the information needed to construct the geometry of space-time consists of the story of the causal structure." ${ }^{, \mathrm{v}}$ By contrast, quantum physics assumes that space and time are independent of the events that take place in them. So, however strange the behavior of matter at the quantum level may be, there is a 
certain simplicity to the causal structure. One way to combine these two theories involves introducing into quantum physics the kind of interdependence between events and the structure of space and time that characterizes the theory of general relativity. In this way, the significance of the causal structure of events in the theory of general relativity is carried over to the account of quantum gravity that Smolin and his fellow researchers propose, and thereby to the whole cosmology based on it. However, Unger and Smolin argue that in order for any such account to be successful, cosmology itself must take a further radical step and revise its understanding of the laws of nature and their relation to time.

Unger and Smolin note that physics is still marked by traces of an absolutism that underpinned Newtonian science, most clearly in the assumption that the fundamental equations of science, and by implication the fundamental reality they describe, are timeless. According to this longstanding orthodoxy, the changing universe can be explained by appealing to what does not change, and the aim of science is to discover laws that are universal and eternal. Far from being merely a matter for philosophical speculation that need not trouble science and working scientists, this assumption has, they argue, led contemporary cosmology into dead ends and wild goose chases. Their aim is to root it out, and to show that cosmology can do perfectly well without it.

\section{ii.}

Although twentieth-century science was marked by at least two decisive breaks with the Newtonian paradigm, in quantum physics and the special and general theories of relativity, the search for a unified law-based account of the universe has remained the norm. In particular, the laws themselves, expressed mathematically, continue to 
be regarded as timeless; which is to say, the laws governing change do not themselves change. Accepting this leaves cosmology facing two fundamental puzzles. First, why are the laws of nature the way they are and not otherwise? Second, why were the initial conditions of the universe as we understand them to have been and not otherwise? The problem is that a scientific account of any given system applies the appropriate laws to the initial conditions without asking where either come from or why they are as they are. There are ways to manage this deficit when dealing with a part of the universe in isolation, but to leave such questions unanswered when dealing with the universe as a whole is to concede that cosmology is radically incomplete. Yet to propose a conclusive "once and for all" answer would invoke a Leibnizian conception of sufficient reason that drags science uncomfortably far from its empirical point of reference. The current orthodoxy leaves cosmology torn between these two unsatisfactory alternatives.

Unger and Smolin's response to this predicament is to challenge the basic assumptions on which it rests, allowing a new possibility to emerge, one in which an adequate cosmological explanation does not have to be "complete" in the Leibnizian sense. Their approach can be encapsulated in what they identify as two cosmological fallacies, a reference both to the fact that they concern cosmology and to the standard objection to the cosmological argument for the existence of God: that it applies to the whole a form of reasoning appropriate only to a part. The first fallacy concerns the Newtonian paradigm according to which to explain how a given system (such as a collection of particles in a box) behaves over time one has to determine the initial conditions (the kind, position, and velocity of all the particles), and then apply the appropriate physical laws. The initial conditions are the starting point for the phenomena that the laws explain, but they are not themselves explained by those 
laws: "they are assumed rather than explained."vi This is fine where the task is to explain a well-defined closed system, because there is always an "outside" for the observer and theoretician to occupy; one that is fictitiously timeless. In principle, what is assumed in the account of one part can then be addressed by another, and the universe gradually explained bit by bit. But when the task is to explain the universe as a whole it is impossible to take a position "outside" the system, and there can be no switching of positions to fill out the account. This shows that the assumption of initial conditions becomes problematic when dealing with the universe as a whole. On their part, the laws that are to explain why the initial conditions of the system develop in a given way are regarded as timeless, unaffected by the changes they govern, and having no history of their own. Like the initial conditions of the configuration space, they are assumed by the explanation that follows, and therefore "to ask why they are what they are is to pose a question that lies in principle beyond the limits of a natural science conforming to the Newtonian paradigm." ${ }^{\text {,vii }}$ Yet the point of cosmology, Unger and Smolin remind us, is to explain everything, and by adopting a model of explanation that makes this impossible science allows itself to remain shaped by metaphysical forms of thought that it professes to oppose. It is by failing to recognize this, or by ducking the challenge, that Unger and Smolin think science commits the first cosmological fallacy.

Where the first cosmological fallacy concerns a mistake in method, the second, which they call the "fallacy of universal anachronism" (Unger and Smolin 2015: 23), arises from negligence over what science actually takes to be the case. It is accepted that the universe is cooling down and that the relatively stable structure described by modern science was preceded by a phase in which energy levels were so extreme that the physical laws as we know them could not have applied. In this 
period, the universe worked in ways we do not recognize and could not derive from observation today. Similarly, it is possible that at some point in the distant future the universe may become quite different to the way it is now, and indeed that there may exist exceptional regions of the universe even now, such as inside black holes, where the laws we see in operation more generally do not hold. The second cosmological fallacy lies in the assumption that the universe we can see now is necessarily a reliable guide to the universe at other times. Unger and Smolin draw a very simple conclusion from all this: that we cannot justify "the immutability of the laws of nature from their overall stability in the observed universe."viii Having set out these two fallacies, Unger and Smolin go on elaborate a broad critique of contemporary cosmology, recommending profound revisions to the way science is conceived and practiced that include reversing the priority of structure over history, and recognizing that there is a narrative element to scientific explanation. I will say a few words about these ideas later, but first I want to focus here on just two points. The first concerns the relation between laws and the phenomena they are intended to explain, and the second concerns causality, and its relation to law.

Science assumes that before a system can be described it must first be partitioned from conditions that are considered to lie outside it. Some of these conditions, such as the precise arrangement of matter a great distance away, can usually be ignored. But other conditions, such as the laws thought to govern the development of the system in question, must be taken into consideration. This works perfectly well when dealing with specific phenomena and small-scale systems, but it becomes problematic when cosmology addresses the universe as a whole. For if, as Unger and Smolin suggest, science should avoid appealing to metaphysical principles, that is, "the explanation for anything in the universe can involve only 
other things that also exist in the universe, ${ }^{\text {,ix }}$ then the distinction between the initial conditions of the universe and the laws that are to govern its development becomes problematic. In this case, what bears on the development of the universe at any point is no more or less than its total state. The same point can be made by considering the extreme conditions of energy and density in the early universe. At this stage, the distinctions between constituents of nature that are familiar to us today had yet to emerge and there was no "established repertory of natural kinds." "Without stable kinds to describe, laws cannot stand apart from the reality they ostensibly govern. As a consequence, they cannot be universal. In fact, in the most extreme circumstances, the range of law tends towards a point where it coincides with the phenomena it is supposed to govern, because there is no reason to assume that the consistency law requires extends any further. ${ }^{\mathrm{xi}}$ In such conditions, again, the distinction between laws of nature and the phenomena they govern breaks down. As Unger and Smolin are quick to point out, this does not entail the breakdown of order into chaotic confusion, because causal connections continue to be effective even where there is no over-arching law to determine how they will occur: "what comes before will always shape what comes later, even if the mechanism of influence may change."xii Rather than moving from a strongly determined universe to one without meaningful laws, Unger and Smolin argue that laws and the phenomena they govern develop in tandem, their difference being more one of degree than of kind. Although the coeval development of laws and phenomena will be most evident in extreme states of the universe where the degrees of structure and regularity we see today have yet to emerge and the difference between laws and phenomena are consequently slight, the reciprocal effect remains even in regions and periods of stability: it is a matter only of degree and historical perspective. 
An obvious objection to raise is that to allow change to be governed by laws that can themselves change is to usher in a crisis in the foundations of science. For if there is no still more fundamental law to determine how laws themselves change, science appears to give up its claim on a final explanation - it can no longer provide the sufficient reason for things being as they are and not otherwise. This is the predicament to which I referred earlier, and which Unger and Smolin call the conundrum of the meta-laws: either there is no law to determine how things change, or there must be a higher order law that we have yet to find. But the truth is that to phrase the problem this way is to phrase it badly, for science is already unable to provide a sufficient reason for things being the way they are, simply because it cannot account for why the laws and the initial conditions of the universe as a whole are the way they are. Recognizing that there is no need to lament the loss of what science never truly had, Unger and Smolin point out that we are accustomed to think that causality depends on laws, but this is not necessarily the case. Rather, "causality exists without laws, which is a way of saying that causal connections have not acquired, or have lost, the repetitious form, over a differentiated range of nature, that makes it possible to distinguish phenomena from laws."xiii As noted already, this was the condition of the early universe, when the distinction between regularities of nature and states of affairs (or laws and initial conditions) could not be made. In the absence of what we think of as law, "states of affairs may have been excited to higher degrees of freedom and allow for a broader range of adjacent possibles than we usually (but not always) observe in the established universe." ${ }^{\text {xiv }}$ Such regularities as there were at this early stage were partial and non-binding, but nonetheless change was not random. As the universe cooled, the structure familiar to us today emerged and regularities became so well established that laws could be separated off 
from the states of affairs they describe, heuristically at least. They could even be mistaken for laws that are eternally fixed, but this would be to ignore variations in the laws themselves that only become visible over longer periods of time. No one region of the universe or period of its history can be counted on to reveal the most basic truths of nature. ${ }^{\mathrm{xv}}$ Instead, Unger and Smolin argue, "we do better to think of the laws of nature as deriving from causal connections rather than to see the latter as deriving from the former, as we are accustomed to do."xvi This is to say, causal structure comes first and laws follow. It is only when causal structure has reached a settled state that laws can be separated from the phenomena they govern. But this can change. Structure, then, derives from history, and not the other way around. But it also both "constrains and enables later historical development."xvii Accordingly, scientific explanation is itself ultimately historical, tracing events and the way they occur back to what came before without expecting to reach a final point where whole the story began and explanation stops. ${ }^{\text {xiii }}$ There is, they suggest, no final answer to the question of why events at a certain point in the history of the universe were as they were, or why the laws that describe their development are what they are. But whereas science that appeals to universal laws has to acknowledge this as an inexplicable limit to its understanding, the model of science that Unger and Smolin propose simply continues to trace conditions and laws back to earlier conditions and laws. In this way, they give up the strictly Leibnizian demand for sufficient reason, while still holding that a reason for why things are as they are and not otherwise can be found, and all this without leaving room for a truth that is in principle beyond the reach of science, and that might be the province of some other, arguably higher, discipline. $^{\text {xix }}$ 


\section{iii.}

I will now tell the story of the precedence of causality to law from the point of view of Lucretius.

Lucretius tells us that his aim in writing De Rerum Natura was to release his fellow human beings from the fear inspired by the belief that their lives were subject to capricious and unpredictable gods. To this end, he encouraged the reader to see, following his explanations, that the natural world was governed by stable laws. If this were to mean that the movement and interactions of atoms are everywhere and always the same, one might object that he simply replaced the willful interventions of gods, ${ }^{\mathrm{xx}}$ without considering all the implications of living in a world governed by absolute laws whose origin is unknown and unknowable. Although such laws may be less terrifying, insofar as they may be understood and events made more predictable, they would still be remote and would not themselves belong to the order they governed. Such a view adopts the vantage point of the rebirth of atomism in early modern science and misses much of what is most novel and interesting in Lucretius. In particular, it runs counter to an aspiration running through his work to explain the world from the world itself, and above all on the basis of the principle that only atoms and void exist. ${ }^{\text {xi }}$

The basic elements of Lucretius' account are simple. The universe is infinite in extent, and has always existed and everything in it is composed of atoms and void. Atoms are infinite in number, but finite in variety and size, and combine to form the ordered world that we see around us. All order emerges as a consequence of chance collisions with no guiding principle or $\tau \varepsilon \dot{\lambda} \mathrm{o}$. Some collisions between atoms lead to combinations that are more stable than others, and some of these recur, and as they do so they form regularities that make subsequent events more or less 
likely. In this way, pockets of order emerge and persist as atoms combine according to these regularities, but nothing lasts forever and all order is destined eventually to break down, releasing atoms to flow off towards new combinations and new forms of order. ${ }^{\text {xii }}$ The laws that shape events are therefore regularities that emerge from the sequences of events themselves, as they are for Unger and Smolin; and, like them, Lucretius proposes that causality precedes law. ${ }^{\text {xiii }}$

How do atoms actually move, collide, and combine? Imagining something like a beginning, Lucretius sees them raining down uniformly through the void in a laminar flow, driven by their own weight, the heavy and the light moving at the same speed. ${ }^{\text {xxiv }}$ The fall of atoms in a laminar flow has a mythical quality to it that reminds me of how, it is said, in Romania they used to begin their old tales: "It was a time and it was no time..." ${ }^{\mathrm{xxv}}$ The account promises both safe harbor and shipwreck. For although the universe has no absolute origin, it has a narrative structure and one can trace events back to an earlier time. Yet in doing so one arrives at a state that contains no information about the initial conditions from which the later universe arose, and next to nothing about the laws that were to give form to that becoming. In this respect the laminar flow plays a role very much like the initial chaos in Hesiod's theogony: lacking all determination, it puts a stop to any narrative driven by the questions "Why this?" and "Where did it come from?"xxvi More specifically, the laminar flow does this in the context of a universe that is temporally infinite. Its purpose is to allay any suspicion that further back there may have been a time in which the initial conditions and the law that governed their development were separate. Instead, the separation of initial conditions and laws that is assumed to be fundamental in the scientific account of any given system becomes problematic, as it is for Unger and Smolin when dealing with the universe as a whole. Moreover, 
Lucretius writes that if the rain of atoms in parallel were not interrupted, then atoms would rain down through the void without colliding, but he does not imply that such an uninterrupted flow actually lasted for any significant period of time: indeed, no period could be significant in a universe that is temporally infinite. The laminar flow has always already been interrupted and, unlike Hesiod's story of the universe, the Lucretian narrative refers back to a state that the universe may not actually have occupied. But whether or not the laminar flow has a place in the chronological series of events, it features in the logical order of the universe. Its primary effect is less to put an artificial stop to the narrative of the universe reaching further and further into the past than to block a particular kind of explanation; that is, an explanation that relies on the separation between laws and the conditions to which they apply. The Lucretian story of the rain of atoms tells us not only that the historical narrative has no true beginning, but also that it unfolds without a fundamental separation between laws and initial conditions.

For order to emerge, atoms must collide, and this comes about by virtue of a spontaneous change in direction that Lucretius variously describes using the verbs depellere, ${ }^{\mathrm{xxvii}}$ declinare, ${ }^{\mathrm{xxviii}}$ and inclinare, ${ }^{\mathrm{xxix}}$ the root of the latter two giving the noun clinamen, ${ }^{\mathrm{xxx}}$ which is often translated as "swerve," but also sometimes retained without translation.

While atoms move by their own weight straight down Through the empty void, at quite uncertain times And uncertain places they swerve [depellere] slightly from their course. $^{\mathrm{xxxi}}$ 
The clinamen gives the primal equilibrium a needed tilt, and as such serves as a kind of first event, albeit one that is uncaused and which thereby stands as a blank counterpart to the laminar flow it disrupts, each operating as a limit to our understanding. Yet in spite of how it may appear, the clinamen is not just an ad hoc device to trigger the processes from which everything will follow in law like fashion. ${ }^{\text {xxii }}$ Such an objection assumes that the clinamen should not really happen: it assumes there is a natural motion from which it departs for no good reason. Could the fall of atoms through the void not be such a natural motion, and would such motion not imply the existence of an underlying law? After all, when left to themselves atoms will move this way of their own accord, ${ }^{\text {xxiii }}$ and this could be described as a kind of natural motion. The truth is it could be so described, but not in the usual sense. According to Newton, a body naturally moves at a constant velocity unless acted on by an external force. When there is a departure from natural motion an explanation is required, and that explanation, which is causal, depends on a law that encompasses both the natural motion and the state to which it is perturbed by the external force: the same laws govern the natural motion of a body, its perturbation, and its motion after the perturbation. But this is not the case in Lucretius. An atom falling through the void by its own weight may be perturbed by a strike from another atom, but the very "first" perturbation is caused by the clinamen, which strictly speaking is not an "external force" since the atom is not struck by anything else. Moreover, once atoms begin to collide, the regularities that emerge take over from the basic principles that atoms fall, collide, and combine. Therefore, there is no law that determines both the "natural" system and the perturbed system: each change in the movement of atoms leads directly or indirectly to a change in the regularities that shape the movement of atoms in the future. So while it is true that 
without the clinamen atoms would not collide and therefore could not combine to form the world we see around us, as a spontaneous deviation in the movement of an atom, the clinamen does not violate any fundamental physical law, because there are none. The fall of atoms as a laminar flow is not law governed, rather it is simply the condition of equilibrium from which order emerges: both ordered states and the "law" that orders them, which is in fact just a regularity that has reached a settled form.

Smolin makes a similar point from the perspective of contemporary cosmology. There is, he writes, symmetry in a system when it can be changed in a certain respect without disturbing the overall character of that system; for example, a sphere is symmetrical with respect to space, because rotating it does not change its shape. As Smolin notes, the systems in classical and quantum mechanics that have symmetries involve an isolated system moving relative to an external frame of reference (Unger and Smolin 2015: 369). But this cannot be replicated with the whole universe because there is nothing relative to which it can move. Invoking Leibniz's principle of the identity of indiscernibles, Smolin observes that "the universe as a whole has no symmetries.”xxxiv But symmetries are associated with properties that are conserved under transformation, and so "it is then proper to regard the great conservation laws of physics - of energy, momentum, and angular momentum - as emergent and approximate. ${ }^{\text {xxxv }}$ As a consequence, an account of the universe as a whole can have no global symmetries or conservation laws, which runs directly counter to the received wisdom that the more fundamental the theory the more symmetry it must have. It turns out that this apparently troubling conclusion points cosmology towards a solution for a persistent and difficult problem. For if symmetry were key to a theory of the universe as a whole, one 
would either have to explain why the symmetry is broken or accept that there is a gap in our knowledge that the theory cannot explain. It is in part to avoid this predicament that Unger and Smolin propose that laws and initial conditions converge when it is a matter of the universe as a whole. They then draw the following conclusion:

Our universe should not be seen as a vast collection of elementary events, each simple and identical to the others, but the opposite, a vast set of elementary processes, no two of which are alike in all details. At this level fundamental principles may be discerned but there are no general laws in the usual sense. ${ }^{\text {xxvi }}$

The basic principles to which Unger and Smolin refer here are higher order regularities that, while not immune from change, change more slowly and help to give form to lower order laws and ultimately to phenomena. They include the principle of least action, and the principle of the conservation of energy. ${ }^{\mathrm{xxxvii}}$ Analogous principles for Lucretius would be those stating that atoms fall by their own weight, and that combinations of atoms are formed as they collide. Such principles provide a general framework within which change occurs but they are not sufficient to determine each interaction. In Unger and Smolin's terms, they do not determine the causal structure of events, which for Unger and Smolin, as for Lucretius, depends on the regularities that form locally in time and space.

Once the rain of atoms down through the void is disrupted by the clinamen, a chain reaction of collisions multiplies and spreads. Turbulence ensues, and from this near chaos degrees of order gradually emerge. Lucretius describes the process as 
follows:

For sure, not by design or intelligence

Did primal atoms place themselves in order,

Nor did they make contracts, you may be certain,

As to what movements each of them should make.

But many primal atoms in many ways

Moving through infinite time up to the present,

Clashing among themselves and carried by their own weight,

Have come together in every possible way,

Tried every combination that could be made;

And so advancing through vast lengths of time,

Exploring every union and motion,

At length those of them came together

Which by a sudden conjunction interfused

Often become the beginnings of great things -

Of earth and sea and sky and living creatures. ${ }^{\text {xxxiii }}$

The movement of atoms is not coordinated and harmonious, as one would expect if there were fundamental laws. Instead, while the fall of atoms ensures that movement of some kind continues, how atoms combine and the arrangement they assume is a matter of chance. The suggestion that the order of the universe, and more specifically the values of the constants in the fundamental equations of physics, may have arisen purely by chance fell out of favor in modern science as the sheer scale of the odds involved became clear. For there to be order in the universe at all, and 
certainly on the scale we can see, the constants have to be set to with such precision that chance no longer seems a compelling explanation. It was in part to address this problem that Smolin first proposed the idea that the laws of nature may evolve across the birth and death of many universes, those universes most likely to give rise to order reproducing in such a way that the value of the physical constants settled closer and closer to the values we see in our own universe. ${ }^{\text {xxix }}$ Lucretius gets around the problem simply by regarding the universe as temporally and spatially infinite, thereby allowing for all permutations to arise at some point, as different worlds form, grow, decay, and disappear. However, there is a principle of selection at work here, too, insofar as those combinations of atoms which produce order survive and are therefore able to give rise to modifications from which there is then a higher chance of relatively stable states emerging. The essential thing in both cases is that order is not determined in advance by fixed laws working on a determinate set of initial conditions. It is the regularities themselves that draw matter into a settled pattern that repeats and in doing so shapes future events.

When they are sufficiently stable, these regularities constitute laws that are descriptive, in the sense that they pick out the patterns of change and stability that have already emerged. But they are also prescriptive, in the sense that they constrain the movement and combination of atoms, and thereby, within limits, the future. As atoms combine and fall into regular patterns of movement, some events become more likely, and some less, overwhelmingly so in certain cases. As Lucretius writes, we see the seasons pass in regular fashion, animal and plant species reproduce, first beards grow and then with age teeth fall out:

For since the causes from the first beginning 
Were of this nature, and from the first beginning

Things happened in this way, in sequence then

And order fixed they even now recur. ${ }^{\mathrm{xl}}$

However, the order is never universally binding. It is significant that Lucretius applies the term "fixed [certo]" here, to the order of events, and not to a law that might be thought to underpin them. Certo means "settled" more than "fixed forever." In particular, it may refer to "what has been agreed" - a fitting sense, given that order emerges from the conjunction of atoms that Lucretius names the foedera natura and Michel Serres describes as an alliance or treaty. ${ }^{x l i}$ Such an alliance cannot last forever, because nothing in the Lucretian universe does: "all things are continually in flux,",xlii and even the present arrangement of the earth, the sea, and the sky are expected eventually to break down and give way to other forms of composition. ${ }^{\text {xliii }}$ For Lucretius, the question of why certain phenomena occur as they do is not, in the end, a question about laws. It is a historical question. In fact, all fundamental questions are historical, because there is nothing changeless to which the changing world can be referred, or against which it can be measured. Order is local; that is, not merely the local manifestation of universal laws and principles, but a singular regularity in which events and the order they exhibit are in continual dialogue. An account of such order will be historical, tracing both the causal series and the causal structure, the sequence of events and the rule permitting the sequence to continue.

Unger and Smolin embrace this conclusion and argue that cosmology will only be able properly to stake its claim to be "the most comprehensive natural science" when it understands itself as fundamentally a historical science. ${ }^{\text {xliv }}$ 
Cosmology must speak not just of things, events, and the laws by which they are determined, but also of the way the laws evolve, and of the changing causal structure that articulates this evolution. Unger and Smolin (Unger especially) are mindful that a model has already become well established in the social sciences and the life sciences, ${ }^{\mathrm{xlv}}$ and acknowledge that their project could be described as bringing such practices to bear on natural science. But it is worth pausing to ask whether the social and life sciences genuinely provide the kind of model actually required by the account Unger and Smolin propose. Evaluating the models of law used in the social and life sciences is too big a task to take on here, but it is possible at least to set out what is at stake.

iv.

If "law" is no longer ideal, universal and fixed, then it needs to be fundamentally rethought, and not just recast in a weakened form. It must not be an essentially changeless law that has had the misfortune to fall into time and then be nudged from one state to another, each time as if fixed for good, until the next change. Such a conception of law would hand down the old assumption that matter is inert and mute, and that it requires organizing principle of some to give it form it and enliven it. Referring to "regularities" is a first step, but the idea that regularity somehow "acts" to sustain a sequence still implies the transcendence of something like a rule to the order of events it governs, which is just what first Lucretius and then Unger and Smolin wish to avoid. The trouble is, the idea of regularity tells us very little about how it sustains itself. The sense of law must properly begin with matter itself and not just be susceptible to change by virtue of matter. On this point, accounts of complexity and emergence offer a way forward, but Michel Serres is particularly 
helpful.

Thinking of the clinamen as the first departure from the laminar flow of atoms raining down through the void, Serres elegantly captures the way that regularities, and thereby laws, emerge when he writes that "the pre-model of the fundamental physics has no laws," but that "as soon as a phenomenon appears, as soon as a body is formed, a law can be expressed."xlvi Borrowing from information theory, he likens the emergence of order in the combination of atoms to the emergence of language, as indeed does Lucretius, ${ }^{x l v i i}$ and observes that "the law repeats the fact itself: as things are composing, the laws express the federated."xlviii The code that describes how atoms move and combine arises "as soon as the deviation from equilibrium takes place," and "determination is nothing but the retention of the code." ${ }^{\text {"xlix }}$ Serres makes no distinction here between code and law, but elsewhere he does, and the difference is significant for the broader account of causality.

Roughly speaking, code and law belong at either end of a process of making sense that begins with matter and ends with science (though science is not the only possible outcome). According to both Lucretius and Serres, everything continually flows, and the only truly basic principle is that everything flows towards equilibrium. Order is the slowing of this return. It is delay. But what causes the delay? And why does a particular order form, and not some other? Serres writes that matter's route back to equilibrium is not direct because it flows along paths, which thereby place a constraint on what states can follow from any given configuration. The path is a regularity. But paths are not fixed. They follow the most direct available route back to equilibrium around the obstacles in their way, and these obstacles are simply conjunctions of other paths - other regularities. ${ }^{1}$ Matter is 
simply caught up in a series of games of its own devising. It gets in its own way, diverting itself, giving itself form. There is no law to determine how this must happen, at least no universal law. Sense begins in the form of code as matter first combines. But such code does not necessarily give rise to causal structure. In L'Incandescent, Serres writes that things act on one another through the forces they exert, but that they also communicate, exchanging code. ${ }^{\text {li }}$ Quite distinct from law, code may be the most ephemeral trace of a sequence that does not last, that matter does not remember, long enough to be established as a regularity that we recognize and record. Code is the material analogue of what Leibniz called tiny perceptions (petites perceptions), the countless events of sensing that fall below the threshold of consciousness. Causal structure is that code which is sufficiently established in the memory of matter to make the history of a given system or locality calculable, and its future predictable.

Serres concludes that alongside the physics we know, which identifies the causal structure of the physical world, there is a second, which attends to code that has not yet become sufficiently regular to warrant speaking of cause and effect, and that may not ever do so. It takes the form of a historical narrative, tracing the sometimes irregular steps from event to event without the guidance of a fixed law. It is a history of the formation, deformation, and reformation of code. Serres doubts that we have anything like this second science, writing that we still do not have an ear for code that has yet to become cause, for "the clamour of things or the background noise of the world." "lii We still need to learn to remember the world as it remembers, to leave our mark on the world as it marks itself. liii However, with their inversion of the priority that physics usually accords to structure over history, and their incorporation into cosmology of the precedence of causal structure over law, 
Unger and Smolin have shown that there are good reasons for science to consider what Serres proposes. In so doing, they have also let us see that Lucretius remains our contemporary.

\section{Bibliography}

Boutroux, É., De la Contingence des Lois de la Nature (Paris: Felix Alcan, 1898).

Buckingham, W., Finding Our Sea Legs: Ethics, Experience and the Ocean of Stories (Kingston upon Thames: Kingston University Press 2009).

Fowler, D., Lucretius on Atomic Motion (Oxford: Oxford University Press, 2002).

Hesiod and Theognis, Theogeny, Works and Days, and Elegies, trans. D. Wender (London: Penguin, 1973).

Lucretius, La Natura delle Cose, trans. L Canali (Milan: Rizzoli, 1990).

Lucretius, On the Nature of the Universe, trans. R Melville (Oxford: Oxford University Press, 1999).

Peirce, C.S., 'The Architecture of Theories', The Monist, 1.2 (1891), pp. 161-76.

Serres, M., La Naissance de la Physique dans le Texte de Lucrèce (Paris: Les Éditions de Minuit, 1977).

Serres, M., The Birth of Physics, trans. J. Hawkes, ed. D. Webb (Manchester: Clinamen Press, 2000).

Serres, M., L'Incandescent (Paris: Éditions Le Pommier, 2003).

Serres, M., Biogée (Paris: Éditions Le Pommier, 2013).

Smolin, L., The Life of the Cosmos (London: Phoenix, 1997).

Smolin, L., Three Roads to Quantum Gravity (London: Weidenfeld and Nicholson, 2000). 
Smolin, L., Time Reborn: From the Crisis in Physics to the Future of the Universe (London: Penguin, 2013).

Unger, R.M., False Necessity: Anti-necessitarian Social Theory in the Service of Radical Democracy (London: Verso 2004).

Unger, R.M., and L. Smolin, The Singular Universe and the Reality of Time (Cambridge: Cambridge University Press 2015).

\section{Notes}

${ }^{\mathrm{i}}$ The title De Rerum Natura [DRN] is normally translated either as On the Nature of the Universe or The Nature of Things, or some close variation. In preparing this paper I have referred to several editions, but have cited the translation by Ronald Melville, published by Oxford University Press.

ii Charles Sanders Peirce, "The Architecture of Theories," p. 164.

iii Émile Boutroux, De la Contingence des Lois de la Nature [Boutroux], p. 2.

iv Although Unger and Smolin co-authored The Singular Universe and the Reality of Time [Universe], the book is divided into two sections, authored individually. Although I will for the most part refer to the section authored by Unger, I will not specify this in my citations, but will note in the text if Unger and Smolin themselves draw the reader's attention to a difference in their views.

${ }^{v}$ Lee Smolin, Three Roads to Quantum Gravity [Gravity], p. 59.

${ }^{\text {vi } U n i v e r s e ~ p . ~} 20$.

vii Ibid.

viii Ibid. p. 267.

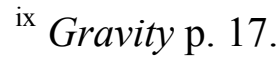

${ }^{\mathrm{x}}$ Universe p. 269. 
${ }^{x i}$ Ibid. p. 270.

xii Ibid. p. 279.

xiii Ibid. p. 270.

${ }^{\text {xiv }}$ Ibid. p. 277.

${ }^{\mathrm{xv}}$ Ibid. p. 212.

${ }^{\text {xvi }}$ Ibid p. 281. Boutroux p. 4 proposes a similar idea, when he asks rhetorically: “do causes merge with laws [les causes se-confondent avec des lois], as, in the end, the doctrine that defines laws as an unchanging relation supposes?"

${ }^{\text {xvii }}$ Universe p. 288.

xviii Ibid. p. 372.

${ }^{\text {xix }}$ Unger and Smolin disagree over this point. Unger prefers to dispense with the idea of sufficient reason altogether, whereas Smolin more cautiously proposes to replace it with a "principle of differential sufficient reason" according to which, in choosing between competing theories, one opts for the one that minimizes questions of the form "Why does the universe have property X?" for which there is no rational response - by which he means a scientific response that relies solely on what is within the universe; see Universe pp. 367-8, 513-5.

${ }^{\mathrm{xx}}$ DRN I.147, II.62.

${ }^{\text {xxi }}$ Ibid. I.418-47.

xxii These ideas are presented at various points in $D R N$, but in particular at V.107, 245-80, 1341-7.

xxiii One reason to think that Lucretius regarded the laws of the universe as fixed is that he refers on a number of occasions to the "deep-set boundary stone" marking a limit to what can be and what cannot, and thereby also a limit to the power of religion and its practitioners to intervene (DRN I.77, II.1087, V.90, VI.66). Although it may be 
tempting to see this as an invocation of invariant laws, it is not necessary to go that far. It would be more consistent with the text as a whole to take the expression "deepset boundary stone" as a reference to the constraints imposed by the basic principles of atomism. For example, everything is born and dies, and this pattern is repeated endlessly across the universe; different stars and planets form and disappear, as do different animals, and the species to which they belong. The principle underlying all of this is that atoms fall, collide, and combine, but this alone does not determine how events in the future will unfold.

${ }^{\text {xxiv }}$ Ibid. II.230-5.

${ }^{x x v}$ Will Buckingham, Finding Our Sea Legs: Ethics, Experience and the Ocean of Stories, p. 90.

${ }^{\text {xxvi }}$ Hesiod writes: "Chaos was first of all [...]" (Hesiod and Theognis, Theogeny, Works and Days, and Elegies, p. 27).

${ }^{\text {xxvii }} D R N$ II.219.

xxviii Ibid. II.221.

${ }^{\text {xxix }}$ Ibid. II.243.

${ }^{\text {xxx }}$ Ibid. II.293.

${ }^{\text {xxxi }}$ Ibid. II.217-19.

xxxii Lucretius appears to endorse the idea that the clinamen is necessary to account for the possibility of free will. Although there is textual support for this reading, the argument is far from convincing, and the case for free will seems badly served by spontaneous deviations over which it can have no control. On the other hand, free will depends on not being determined entirely by external stimuli, and the broader account of order in which the clinamen plays a vital part involves a conception of order as local that is consistent with the mind having regularities of its own. The will would be 
the expression of regularities that are neither wholly determined by nature, nor purely spontaneous. Understood in this way, the clinamen does make an account of free will possible, but not the one that is most obvious. As Lucretius describes it, free will is an example of more general processes that are marked by greater or lesser degrees of self-regulation, rather than as the exception in world governed by fixed laws. xxxiii Ibid. II.202.

${ }^{\text {xxxiv }}$ Universe p. 369.

${ }^{x x x v}$ Ibid. p. 370.

xxxvi Ibid. p. 371.

${ }^{\text {xxxvii }}$ Unger and Smolin also refer to the principle of the conservation of momentum, the principle of the degradation of energy (Carnot's principle), and the principle of the invariance of the laws of nature for fixed observers or observers in uniform motion; ibid. p. 285.

${ }^{\text {xxxviii }} D R N$ V.419-31; Lucretius give a similar description a few pages earlier at ibid. V.187-93.

${ }^{\text {xxxix }}$ Lee Smolin, The Life of the Cosmos. Unger and Smolin put it this way: "causal continuity between successive universes, or between successive periods in the history of the one real universe, may be stressed but never broken" Universe p. 111.

${ }^{\mathrm{xl}} D R N$ V.677-9.

${ }^{x l i}$ Michel Serres, The Birth of Physics [Birth], p. 113.

${ }^{x l i i} D R N$ V.280.

xliii $D R N$ V.91-7.

${ }^{\text {xliv }}$ Universe p. 42.

${ }^{x l v}$ Ibid. p. 71-3.

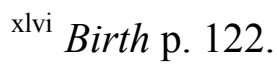


xlvii $D R N$ II.686-98.

xlviii Birth p. 123; I have modifed the translation slightly here. The French runs "La loi répète le fait même: pendant que se composent les choses, les lois disent le fédéré" (Michel Serres, La Naissance de la Physique dans le Texte de Lucrèce, p. 152).

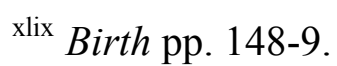

${ }^{1}$ Ibid. p. 51.

${ }^{\text {li }}$ Michel Serres, L'Incandescent, p. 60.

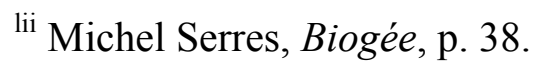

liii L'Incandescent p. 60. 